\title{
UNBOUND AMINO ACID CONCENTRATIONS IN PLASMA, ERYTHROCYTES, LEUKOCYTES AND URINE OF PATIENTS WITH LEUKEMIA *
}

\author{
By RAPIER H. McMENAMY, CHARLES C. LUND and DONALD F. H. WALLACH \\ (From the Department of Biological Chemistry and the Department of Surgery, Harvard \\ Medical School, The Fifth Surgical [Harvard] Service of the Boston City Hospital, \\ Boston, Mass.)
}

(Submitted for publication May 19, 1960 ; accepted July 28, 1960)

The distribution of unbound amino acids in the plasma and blood cells of patients with leukemia may be expected to reflect abnormalities in both the concentrating ability of the cells for the amino acids and in the amino acid metabolism. The distribution of unbound amino acids in the plasma and blood cells of normal subjects has been reported in an earlier communication (1). Studies of the distribution of unbound amino acids in leukemic bloods do not appear to have been previously made, although Kelley and Waisman (2) have studied plasma concentrations and NourEldin and Wilkinson (3) have studied the relative concentrations of several amino acids in the leukocytes of leukemic patients. Some qualitative variations in amino acid concentrations in leukocytes from patients with different types of leukemia have also been reported by Rouser (4).

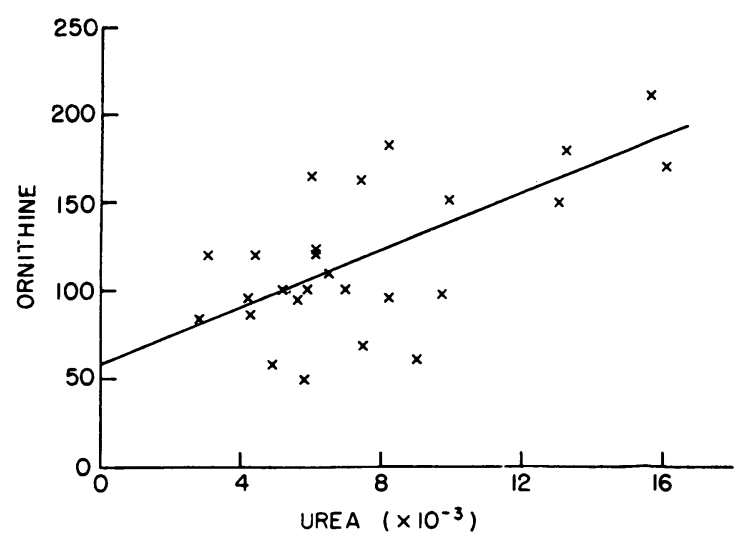

Fig. 1. Comparison of CONCENTRATIONS OF ORNiTHINE AND UREA IN PLASMA OF LEUKEMIC PATIENTS. Micromoles per kilogram of water; line drawn by least squares.

* Aided by Grant C-2497 from the National Cancer Institute, Bethesda, Md.

\section{METHODS}

The methods used for collection of the blood and the urine specimens, and for the analysis of the unbound amino acids were the same as those used for normal subjects (1). All bloods were drawn at the end of an approximate 14 hour fast, and all urines were collected during the last 8 hours of this period.

The notations used for expressing the variability of the data and for expressing the results from tests of different hypotheses are the same as those used previously. The level of significance, $\alpha$, was established at 0.05 . The $\beta$ error was estimated for each evaluation where a significant difference was detected (1).

\section{RESULTS}

Unbound amino acid concentrations in plasma of leukemic patients

The analyses of 32 plasma specimens from 23 patients with various types of leukemia are given in Table I (see Case Histories; analyses L18 and M2 were lost). With the exception of arginine, to be discussed later, there were no differences in the plasma levels that could be associated with any particular type of leukemia or its treatment. To identify the patients with high or low plasma concentrations, the fourth, and fifth columns of Table I list, respectively, the analyses that were less than and greater than $2 \mathrm{SD}$ from the mean found for normal subjects. This latter distinguishes the analyses which differ from the normal mean at approximately the 0.05 level of significance.

Both the ornithine and urea concentrations were found to be high in the leukemic plasmas. Except for one patient, J.W., the increase in ornithine concentration correlated very well with the increase in plasma urea values (see Figure 1). The product moment correlation coefficient, $\mathrm{R}$, calculated for a correlation between ornithine and urea concentrations in plasma was found to be 
TABLE I

Concentration of unbound amino acids in the plasma of leukemic patients

\begin{tabular}{|c|c|c|c|c|c|}
\hline & $\begin{array}{c}\text { No. of } \\
\text { analyses }\end{array}$ & Mean & pм* & $\begin{array}{c}\text { Analyses with } \\
\text { values 2SD } \\
\text { less than } \\
\text { normal mean } \dagger\end{array}$ & $\begin{array}{l}\text { Analyses with values } 2 \text { SD higher } \\
\text { than normal mean } \dagger\end{array}$ \\
\hline & & $\mu$ moles $/ \mathrm{kg}$ water & & & \\
\hline Alanine & 32 & $336 \pm 21 \ddagger$ & $\mathrm{SL}(0.40)$ & L13 & G10 \\
\hline$\alpha$-Amino- $n$-butyric acid & 25 & $27 \pm 3$ & ns & 0 & G13 \\
\hline Arginine\$ & 27 & $68 \pm 4$ & ns & 0 & 0 \\
\hline Glutamic acid & 32 & $<\overline{33}$ & ns & $\mathbf{0}$ & $\mathrm{G} 10,12,13$ \\
\hline Glutamine & 32 & $514 \pm 15$ & ns & $\mathbf{0}$ & 0 \\
\hline Histidine & 30 & $89 \pm 5$ & ns & 0 & 0 \\
\hline Lysine & 32 & $217 \pm 9$ & ns & L13 & 0 \\
\hline Methionine & 25 & $22 \pm 2$ & ns & 0 & L11 \\
\hline Ornithine & 29 & $121 \pm 8$ & $\mathrm{SH}(0.01)$ & $\mathbf{0}$ & $\mathrm{G} 10,12, \mathrm{~L} 3,7,8,9,15,16,17$ \\
\hline Phenylalanine & 31 & $65 \pm 5$ & ns & 0 & G10, L7, 8, 9 \\
\hline Proline & 32 & $201 \pm 13$ & ns & 0 & $\mathrm{G} 7,13,14$ \\
\hline Threonine & 30 & $167 \pm 7$ & ns & $\mathrm{L} 10 \mathrm{a}, 13$ & $\mathrm{G} 2,10, \mathrm{~L} 5,11$ \\
\hline Tyrosine & 32 & $71 \pm 4$ & ns & M1, L11 & $\mathrm{G} 7,10,11, \mathrm{~L} 4$ \\
\hline Valine & 32 & $199 \pm 9$ & ns & M1 & L4 \\
\hline Ethanolamine & 32 & $<\overline{16}$ & high & 0 & $\mathrm{G} 4,7,8,13, \mathrm{~L} 3,8,13,15$ \\
\hline Leucine plus isoleucine & 30 & $209 \pm 14$ & ns & 0 & $\mathrm{G} 7,10,13$ \\
\hline Serine plus glycine & 31 & $664 \pm 42$ & ns & $\mathrm{G} 3,7,10 \mathrm{a}$ & $\mathrm{G} 2,10, \mathrm{~L} 7,15$ \\
\hline Urea & 30 & $8,000 \pm 877$ & $\mathrm{SH}(0.05)$ & G2, L10a & G10, 13, M1, L5-9, 13, 16, 17 \\
\hline$\beta$-Amino isobutyric acid & 2 & $20 \overline{2 \|}$ & high & 0 & $\mathrm{G} 13, \mathrm{L1}$ \\
\hline
\end{tabular}

* Comparison of the mean value of the patients with the mean value of normal subjects $(1)$; ns = not significantly different; $\mathrm{S}=$ significantly different; $\mathrm{H}$ and $\mathrm{L}$ indicate high and low values respectively, in the patient analyses; the $\beta$ error is placed in parentheses.

$t$ Taken from reference (1).

$\ddagger$ Standard deviation of the mean.

$\$$ The mean value for arginine in chronic granulocytic leukemia $(55 \pm 6.6)$ was significantly lower than the mean value in chronic lymphocytic leukemia $(85 \pm 4.6)$.

$\|$ Less than 50 in the other patient analyses.

highly significant, with a probability of correlation equal to 0.999. Patient J.W. (assay G13), in whom the ornithine concentration was normal but the urea concentration very high, had renal insufficiency and therefore was not necessarily producing large amounts of urea. Plasma urea levels of this patient were $26,000 \mu$ moles per $\mathrm{kg}$ water compared with a normal value of 5,380 ; the excretion rate of urea was $3,800 \mu$ moles per hour compared with a normal excretion of 11,450.

Ethanolamine was found in eight specimens of plasma from eight patients; it was never found in any of the analyses of normal subjects. $\beta$-Amino isobutyric acid was found in two analyses (G13 and L1). This substance also was not found in the plasma of normal subjects and we know of no reports of its being found by others. The only substance in low concentration in the plasma of the patients was alanine.

Arginine concentrations were observed to be low in the plasma of chronic granulocytic leukemic patients by Kelley and Waisman (2). Our determinations of arginine in such patients were somewhat lower, but not significantly lower than the arginine values found in normal subjects (1). In chronic lymphocytic leukemia the arginine concentrations tended to be slightly higher than those found in normal subjects. Comparison of the means of the arginine values of these two groups of patients showed their differences to be significant.

Kelley and Waisman also reported significantly higher values for proline and phenylalanine in leukemic patients. The mean concentrations for these two substances in our patients were moderately higher but not significantly higher than those found in normal subjects. High concentrations of glutamic acid and alanine in chronic leukemic patients or low concentrations of threonine and high concentrations of tyrosine in acute leukemic patients, which had been observed by Kelley and Waisman (2), were not found in the current study. 
Unbound amino acids in erythrocytes of leukemic patients

The concentrations of unbound amino acids found in the erythrocytes are presented in Table II (assays G9 and L18 were lost). The erythrocyte-plasma ratios are presented in Table III (assay G9, M2 and L18 not included). As with the plasma analyses, values less than, or greater than, $2 \mathrm{SD}$ from the normal mean are listed in the fourth and fifth columns of these tables. With the exception of ergothioneine (discussed below), there were no patterns in amino acid concentrations that could be related to the types of leukemia or to the treatment of the patients. The total unbound amino acid concentrations were approximately 10 per cent higher in the erythrocytes of the patients than in normal subjects. Most of this increase was attributable to glutamic acid and serine plus glycine which were 50 per cent and 40 per cent higher, respec- tively. Four other substances, ornithine, proline, ethanolamine and urea were also significantly higher. On the other hand the erythrocyte-plasma ratios of only alanine and serine plus glycine were higher than those found in normal subjects. The glutamic acid ratio could not be calculated in view of the absence of this substance in plasma. Ornithine and urea were therefore higher in both the plasma and erythrocytes of the leukemic patients. The same was probably true for proline; its mean concentration was elevated in both the plasma and erythrocytes but only in the erythrocytes was it elevated significantly above the normal mean. The high erythrocyte-plasma ratio for alanine was attributable to the low plasma values for this substance. Serine plus glycine was high in the erythrocytes but showed no change in plasma concentration. The high values of taurine found in the erythrocytes are undoubtedly due to a greater leukocyte contamination in the patients' erythro-

TABLE II

Concentrations of unbound amino acids in erythrocytes of leukemic patients

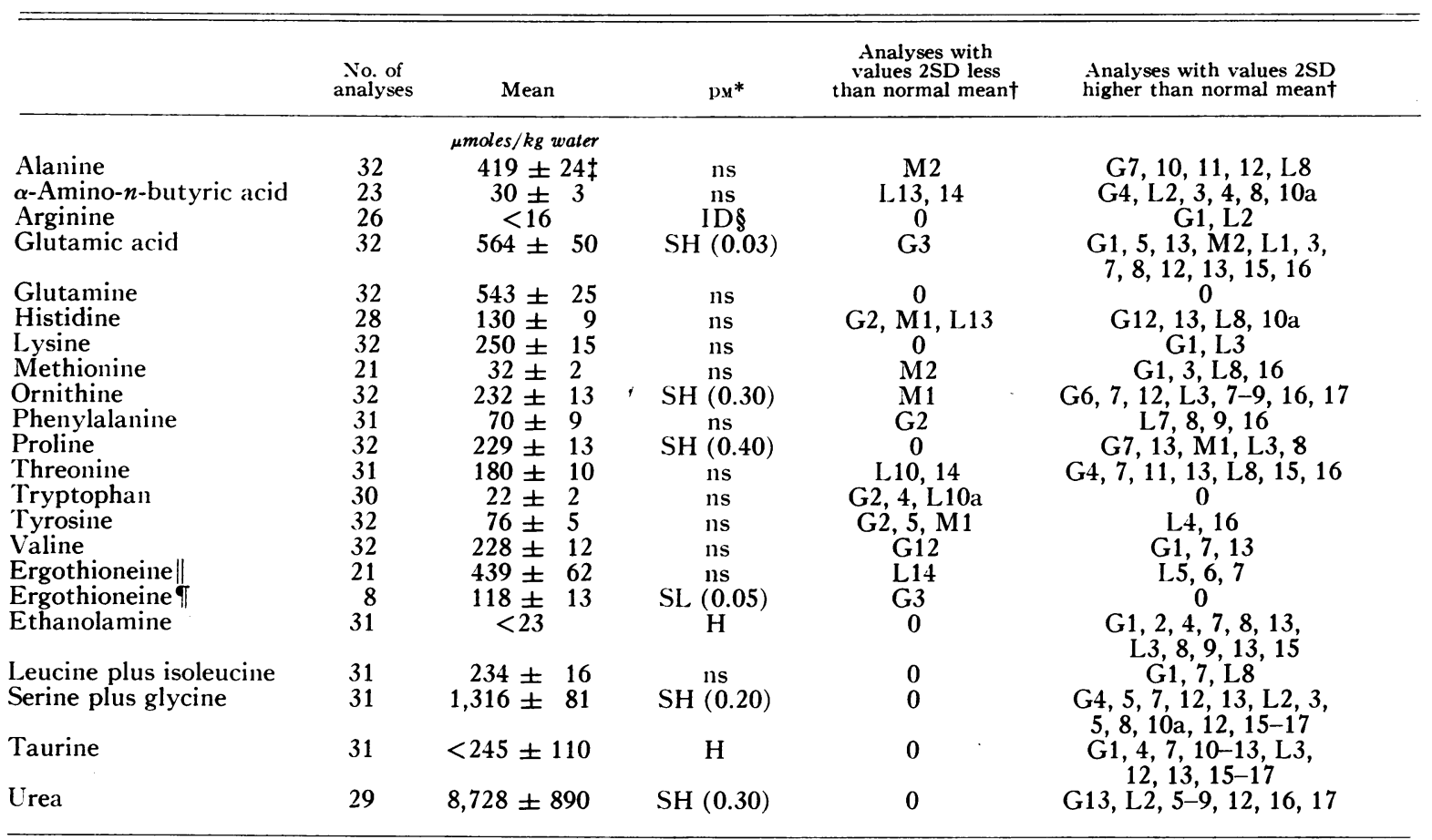

* See footnote to Table I.

$\dagger$ Taken from reference (1).

$\ddagger$ Standard deviation of the mean.

$\$$ Indeterminate.

II Ergothioneine analyses from all patients except those with chronic granulocytic leukemia.

II Ergothioneine analyses from chronic granulocytic leukemic patients. 
TABLE III

Erythrocyte-plasma ratio of unbound amino acids in leukemic patients

\begin{tabular}{|c|c|c|c|c|c|}
\hline & $\begin{array}{l}\text { No. of } \\
\text { analyses }\end{array}$ & Mean & $\mathrm{pm}^{*}$ & $\begin{array}{c}\text { Analyses with } \\
\text { values 2SD } \\
\text { less than } \\
\text { normal mean } \dagger\end{array}$ & $\begin{array}{l}\text { Analyses with values } 2 \mathrm{SD} \\
\text { higher than normal mean } \dagger\end{array}$ \\
\hline Alanine & 31 & $\begin{array}{c}\text { mmoles } / \mathrm{kg} \text { water } \\
1.32 \pm .05 \ddagger\end{array}$ & SH $(0.13)$ & 0 & $\begin{array}{l}\mathrm{G} 1,2,3,7,12,13, \\
\mathrm{M} 1, \mathrm{~L} 8,9,10 \mathrm{a}, 13,16\end{array}$ \\
\hline$\alpha$-Amino- $n$-butyric acid & 19 & $1.31 \pm .16$ & ns & L14 & L2, $8,10 a$ \\
\hline Glutamine & 30 & $1.09 \pm .06$ & ns & 0 & 0 \\
\hline Histidine & 26 & $1.43 \pm .09$ & ns & 0 & L8 \\
\hline Lysine & 30 & $1.19 \pm .08$ & ns & 0 & $\mathrm{G} 1,3$ \\
\hline Methionine & 20 & $1.68 \pm .15$ & ns & 0 & 0 \\
\hline Ornithine & 28 & $2.15 \pm .14$ & ns & G10 & 0 \\
\hline Phenylalanine & 29 & $1.10 \pm .05$ & ns & 0 & 0 \\
\hline Proline & 31 & $1.18 \pm .05$ & ns & 0 & $\mathrm{~L} 8,12$ \\
\hline Threonine & 29 & $1.17 \pm .07$ & ns & 0 & $\mathrm{G} 4,7, \mathrm{~L} 8,11$ \\
\hline Tyrosine & 31 & $1.12 \pm .06$ & ns & 0 & $\mathrm{G} 12, \mathrm{~L} 8,16$ \\
\hline Valine & 31 & $1.24 \pm .06$ & ns & 0 & $\mathrm{G} 1,12, \mathrm{~L} 8,12,15$ \\
\hline Ethanolamine & 8 & $1.48 \pm .25$ & ID & & \\
\hline Leucine plus isoleucine & 30 & $1.18 \pm .07$ & ns & G6 & $\mathrm{G} 12, \mathrm{~L} 8$ \\
\hline Serine plus glycine & 29 & $2.14 \pm .16$ & $\mathrm{SH}(0.10)$ & G10 & $\mathrm{G} 3,5,7,12,13, \mathrm{~L} 5,10 \mathrm{a}, 14$ \\
\hline Urea & 28 & $1.13 \pm .05$ & ns & M1 & $\mathrm{G} 2, \mathrm{~L} 10 \mathrm{a}, 12$ \\
\hline
\end{tabular}

* See footnote to Table I.

$\dagger$ Taken from reference (1).

I Standard deviation of the mean.

$\$$ Indeterminate.

cytes. The very high levels of glutamic acid found in the erythrocytes will be further discussed below.

Iyer (5) has reported marked increases in concentrations of alanine, glutamic acid, glutamine, and serine plus glycine in red cells of patients with iron deficiency anemia. There was no evidence that any of our patients had iron deficiency anemia but several of them had moderate to severe anemia associated with their leukemia. The specimens of anemic patients showed no consistent variation from the specimens of patients with no anemia with regard to any of the amino acids.

The concentrations of ergothioneine found in the erythrocytes of the patients with chronic granulocytic leukemia were much lower than those found in other leukemic patients or in normal subjects. Since almost nothing is known of ergothioneine function in mammalian cells the significance of this striking difference is not clear.

\section{Abnormal concentrations of leukocyte amino acids which were common to most of the leukemic pa- tients}

Changes in concentration of four substances in the leukocytes of the patients, when compared with normal subjects, were characteristic of leukemia without regard to the kind of leukemia and, except for treatment with Chlorambucil, ${ }^{1}$ were independent of the type of treatment (see Tables IV, V, VI and VII). These were O-phosphoethanolamine, glutamic acid, proline and ornithine. Discussions of each of these follow.

O-phosphoethanolamine concentrations were found to be very high in the leukocytes of most leukemic patients; values higher than the normal means were found in every patient sample in which O-phosphoethanolamine was measured. All untreated chronic lymphocytic leukemic patients, acute granulocytic leukemic patients, and monocytic leukemic patients had O-phosphoethanolamine concentrations which were higher by more than $2 \mathrm{SD}$ of the normal mean. It was also high in patients after treatment with X-ray, TEM 2 and nitrogen mustard. ${ }^{3}$ Its concentration tended to be less high in chronic granulocytic patients; only one patient in six (G1) had values higher than $2 \mathrm{SD}$ of the normal mean. O-phosphoethanolamine was not determined in the leukocytes of Patients G3, 4, 7 and 8. Its concentration was normal in two cases after treatment with Chlorambucil. Elevated concentrations of O-phosphoetha-

\footnotetext{
14 -[p-bis (2-chloroethyl) aminophenyl]butyric acid.

2 2,4,6-Triethyleinimino-s-triazine.

3 2,2'-Dichloro $\mathrm{N}$-methyldiethylamine.
} 
nolamine had previously been observed by NourEldin and Wilkinson in the leukocytes of some leukemic patients (3). In addition to this, Outhouse (6) as early as 1936, had found increased amounts of O-phosphoethanolamine in many malignant tissues. It is also highly significant that other patients, such as those with leukemoid reaction, polycythemia vera, leukocytosis following accidental cobalt-radiation, malignant carcinoid, congenital anemia, spherocytosis and general emaciation did not show elevated O-phosphoethanolamine levels. ${ }^{4}$

Glutamic acid concentrations had been found to be elevated in the leukocytes of leukemic patients by Nour-Eldin and Wilkinson (3). In the present study the mean concentration for glutamic acid in the granulocytic, monocytic and untreated chronic lymphocytic leukemic patients was more than twice as high as the mean concentration found in normal subjects. In 13 of the 24 patients in these categories glutamic acid analyses were higher than the normal mean by more than 2 SD. Leukocyte glutamic acid concentrations were also very high in two analyses conducted on a patient one and two days after extensive irradiation. On the other hand, only one of the six patients under treatment with chemotherapeutic agents had an elevated glutamic acid value. The high glutamic acid values in the leukocytes in conjunction with the high concentrations in the erythrocytes of these leukemic patients emphasizes that the metabolism of this amino acid is critically affected in leukemia. High glutamic acid values have also been noted in other malignant tissues $(7,8)$. It was not found to be characteristically elevated in either the erythrocytes or leukocytes of the nonleukemic patients listed above.

Proline concentrations also were high in the leukocytes of the leukemic patients, particularly when compared with the concentrations of the other amino acids. It was higher than $2 \mathrm{SD}$ of the normal mean in five patients with granulocytic leukemia (category $a$, see below); it was low in concentration in only one patient, that of assay L3, where the unbound amino acid concentrations were almost all very low. Proline concentrations were also elevated in the erythrocytes of the leukemic patients (Table II). Since glutamic acid

\footnotetext{
4 Unpublished studies.
}

and proline have interrelated pathways of metabolism (9), a correlation study by regression analysis was conducted. This study did not, however, support a relationship between these two substances in either the erythrocytes or leukocytes.

Low ornithine concentrations were observed in the leukocytes of many of the leukemic patients. Ornithine was elevated in assays of only two patients, L6 and L8. However, in both of these analyses the other amino acid concentrations were increased severalfold. Ornithine concentrations were less than $2 \mathrm{SD}$ of the normal mean in 15 analyses out of 29. This low level of ornithine in the leukocytes becomes even more striking in view of the higher than normal concentrations of ornithine found in the plasma and erythrocytes of these same patients.

Arginine concentrations in the leukocytes of the patients were variable. In most instances no arginine was found. However, in a few patients (G1, G11, L1, L6) high concentrations of arginine were found (roughly $1,000 \mu$ moles per $\mathrm{kg}$ water). No significance can be attributed to this finding, since similar irregular arginine values had been found in two of the leukocyte analyses of normal subjects (1).

\section{Abnormal concentrations of leukocyte amino acids which depended upon the type of leukemia or its treatment}

The concentration of the amino acids in the leukocytes of the leukemic patients, other than the four amino acids discussed above, showed considerable variation. In some instances the variation could be correlated with the type of leukemia and its treatment. For the purpose of this evaluation the patients have been grouped into four categories: a) granulocytic and monocytic leukemia, $b$ ) untreated chronic lymphocytic leukemia (untreated patients were classified as those who had had no chemotherapy or X-ray irradiation, or had not had such treatment for a period of four months preceding the assay), ${ }^{5} c$ ) chronic lympho-

\footnotetext{
5 There were also included in category $b$ patients who had been started on treatment with Chlorambucil within eight days before the assay. Treatment with Chlorambucil usually does not result in immediate changes as indicated by white count depression. Furthermore, in every instance the analyses from patients in this early stage of treatment were similar to the untreated cases.
} 
TABLE IV

Concentration of unbound amino acids in leukocytes of granulocytic and monocytic leukemic patients *

\begin{tabular}{|c|c|c|c|c|c|}
\hline & $\begin{array}{l}\text { No. of } \\
\text { analyses }\end{array}$ & Mean & pmt & $\begin{array}{l}\text { Analyses with } \\
\text { values } 2 S D \\
\text { less than } \\
\text { normal mean }\end{array}$ & $\begin{array}{l}\text { Analyses with values } \\
2 \mathrm{SD} \text { higher than the } \\
\text { normal mean } \neq\end{array}$ \\
\hline \multicolumn{6}{|c|}{ 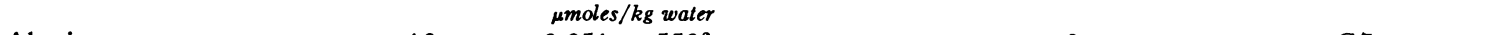 } \\
\hline Alanine & 13 & $3,351 \pm 5538$ & ns & 0 & G7 \\
\hline Arginine & 11 & $<368 \pm[99]$ & ns & 0 & 0 \\
\hline Glutamic acid & 13 & $6,048 \pm 875$ & $\mathrm{SH}(0.3)$ & 0 & $\mathrm{G} 1,5,6,7,11, \mathrm{M} 1,2$ \\
\hline Glutamine & 13 & $2,844 \pm 405$ & ns & G9 & $\mathrm{G} 1$ \\
\hline Histidine & 10 & $546 \pm 110$ & ns & G9, 13, M2 & 0 \\
\hline Lysine & 13 & $1,947 \pm 214$ & ns & 0 & 0 \\
\hline Methionine & 10 & $<450 \pm[51]$ & ns & 0 & 0 \\
\hline Ornithine & 10 & $<1,310 \pm[141]$ & $\mathrm{SL}(0.25)$ & $\mathrm{G} 4,7,9$, & 0 \\
\hline Phenylalanine & 13 & $683 \pm 73$ & ns & 0 & 0 \\
\hline Proline. & 13 & $1,378 \pm 127$ & $\mathrm{SH}(0.10)$ & 0 & $\mathrm{G} 1,3,7,13, \mathrm{M} 1$ \\
\hline Threonine & 11 & $1,788 \pm 214$ & ns & G9 & 0 \\
\hline Tryptophan & 13 & $171 \pm 13$ & ns & 0 & 0 \\
\hline Tyrosine & 13 & $565 \pm 75$ & ns & 0 & 0 \\
\hline Valine & 13 & $1,366 \pm 130$ & ns & G9 & 0 \\
\hline Ethanolamine & 13 & $<286 \pm[54]$ & ns & 0 & 0 \\
\hline Leucine plus isoleucine & 13 & $2,494 \pm 322$ & ns & 0 & $\mathrm{G} 3,11$ \\
\hline Serine plus glycine & 12 & $9,819 \pm 1,650$ & ns & 0 & 0 \\
\hline Taurine & 13 & $37,211 \pm 3,730$ & ns & 0 & $\mathrm{G} 1,11, \mathrm{M} 1$ \\
\hline O-phosphoethanolamine & 10 & $10,263 \pm 2,610$ & $\mathrm{SH}(0.50)$ & 0 & $\mathrm{G} 1,5,6, \mathrm{M} 1,2$ \\
\hline Cell volume\| & 12 & $0.569 \pm 0.050$ & ns & G13 & 0 \\
\hline
\end{tabular}

* Patient assays G1-11, 13, M1, 2.

† See footnote* to Table I.

\pm Taken from reference (1).

$\S$ Standard deviation of the mean. Values in brackets are approximate.

II Volume of one billion leukocytes.

cytic leukemia treated within the four month period preceding the assay by chemotherapeutic agents, and $d$ ) chronic lymphocytic leukemia treated by radiation one or two days before the assay. Tables IV, V, VI and VII present the results obtained in the study of these various categories.

a) Granulocytic and monocytic leukemia. The results of the determinations of the unbound amino acids in the leukocytes of the granulocytic and monocytic leukemic patients are given in Table IV. High concentrations of glutamic acid, O-phosphoethanolamine and proline, and a low concentration of ornithine, all of which have been already found in most leukemic patients, were the only differences from normal subjects noted in these analyses. Furthermore, when examined with respect to the types of leukemia grouped in Table IV (chronic granulocytic leukemia, acute granulocytic leukemia, subacute granulocytic leukemia and monocytic leukemia) there were no patterns that could be associated with any one type of leukemia. Treatment of the patients by Myleran, 6-mercaptopurine, Meticorten, testoster- one or spray X-ray of the spleen five days before the analysis caused no recognizable changes in amino acid concentrations in the leukocytes of this group of patients.

The packed-cell volumes of the leukocytes of the granulocytic and monocytic patients were found to be similar to those of normal subjects. Platelet contamination occurred to an appreciable extent in analyses G2 and G3 (25 platelets to approximately 1 leukocyte). Comparison of the amino acid concentrations found in platelets ${ }^{6}$ with those in leukocytes showed that this contamination would not have affected the leukocyte values by more than 15 per cent and no allowance was made for it. One would expect the error induced by platelet contamination to be largely compensated for in the packed-cell volume measurements which were used to express the concentration of the amino acids and which included the volumes of both the platelets and the leukocytes.

b) Untreated chronic lymphocytic leukemia. Table $\mathrm{V}$ presents the results of 11 analyses of leukocytes from 10 patients with chronic lympho-

\footnotetext{
${ }^{6}$ Unpublished experiments.
} 
cytic leukemia who had not had chemotherapy or $\mathrm{X}$-ray treatments, or who had not had such treatment for a period of four months preceding the assay. Only alanine, proline, tyrosine and probably arginine were at concentrations comparable with those in the leukocytes of normal subjects. Glutamic acid, O-phosphoethanolamine and ethanolamine were at very high concentrations. Excluding these seven substances the average concentrations of the remaining amino acids were 50 per cent less than those of normal subjects. Glutamine concentration was only 40 per cent of that found in normal leukocytes. This substance was also found to be slightly lower in the erythrocytes of the leukemic patients, but it was not lower in the leukocytes of granulocytic and monocytic leukemias (category a) Rouser (4) and others (8) noted a tendency for low glutamine values in malignant tissues and have discussed its possible significance.

A serious drawback in the current study of patients with lymphocytic leukemia was the failure to obtain analyses of pure lymphocytes from normal subjects. The lymphocytes comprise not more than 15 per cent of the total packed-cell volume in normal blood analyses. We have therefore no accurate estimate of the unbound amino acid concentrations in normal lymphocytes and could only compare the concentration of the amino acids in the lymphocytes of these patients with normal leukocytes which include different cell types. In the study of the concentrations of unbound amino acids in treated lymphocytic leukemic patients, to be discussed in the following sections, large changes were observed, which depended upon the patients' treatment. For this reason it was very helpful to know the concentrations of the amino acids in the leukocytes of untreated patients.

c) Chronic lymphocytic leukemia after treatment with chemotherapeutic agents. In this category are included three patients who had been treated with 4-[p-bis (2-chloroethyl)aminophenyl] butyric acid (Chlorambucil, Burroughs Wellcome; two analyses were conducted on one patient after two different periods of treatment); one patient who had been treated with 2,4,6-triethyleneimino-striazine (TEM, Lederle); and one patient who had been treated with nitrogen mustard $\left(2,2^{\prime}\right.$ -

TABLE V

Concentration of unbound amino acids in leukocytes of untreated chronic lymphocytic leukemic patients *

\begin{tabular}{|c|c|c|c|c|c|}
\hline & $\begin{array}{c}\text { No. of } \\
\text { analyses }\end{array}$ & Mean & pis $\dagger$ & $\begin{array}{l}\text { Analyses with values } \\
\text { 2SD less than } \\
\text { normal mean } \ddagger\end{array}$ & $\begin{array}{l}\text { Analyses with values } \\
2 \text { SD higher than } \\
\text { normal mean } f\end{array}$ \\
\hline & & $\mu$ moles $/ \mathrm{kg}$ water & & & \\
\hline Alanine & 11 & $2,739 \pm 257 \S$ & ns & 0 & 0 \\
\hline Arginine & 10 & $<151 \pm[23]$ & ns & 0 & 0 \\
\hline Glutamic acid & 11 & $5,236 \pm 640$ & $\mathrm{SH}(0.45)$ & 0 & $\mathrm{~L} 2,5,9,10 \mathrm{a}, 12,13$ \\
\hline Glutamine & 11 & $1,092 \pm 97$ & $\mathrm{SL}(0.05)$ & $\mathrm{L} 10,12,15$ & 0 \\
\hline Histidine & 11 & $<360 \pm[53]$ & SL $(0.10)$ & $\mathrm{L} 9,10,10 \mathrm{a}, 12,15$ & 0 \\
\hline Lysine & 10 & $977 \pm 112$ & SL $(0.10)$ & $\mathrm{L} 10,12$ & 0 \\
\hline Methionine & 8 & $<188 \pm[21]$ & SL $(0.30)$ & 0 & 0 \\
\hline Ornithine & 10 & $1,169 \pm 146$ & SL $(0.20)$ & $L 5,9,10,11,12,15$ & 0 \\
\hline Phenylalanine & 10 & $<312 \pm[20]$ & SL $(0.20)$ & 0 & 0 \\
\hline Proline & 11 & $670 \pm 65$ & ns & 0 & 0 \\
\hline Threonine & 10 & $1,166 \pm 148$ & SL $(0.05)$ & $\mathrm{L} 10,12,13,15,18$ & 0 \\
\hline Tryptophan & 11 & $<126 \pm[20]$ & SL $(0.50)$ & $\mathrm{L} 10,15$ & 0 \\
\hline Tyrosine & 11 & $<313 \pm[44]$ & ns & 0 & 0 \\
\hline Valine & 11 & $709 \pm 109$ & SL $(0.30)$ & $\mathrm{L} 12,15$ & 0 \\
\hline Ethanolamine & 11 & $<431 \pm[129]$ & high & 0 & L9, 11 \\
\hline Leucine plus isoleucine & 9 & $<896 \pm[148]$ & $\mathrm{SL}(0.10)$ & $\mathrm{L} 12,15,16$ & 0 \\
\hline Serine plus glycine & 11 & $7,235 \pm 790$ & SL $(0.40)$ & 0 & 0 \\
\hline Taurine & 11 & $15,233 \pm 1,410$ & $\mathrm{SL}(0.20)$ & 0 & 0 \\
\hline O-phosphoethanolamine & 11 & $9,282 \pm 1,070$ & $\mathrm{SH}(0.02)$ & 0 & $\mathrm{~L} 2,5,9,10,10 \mathrm{a}, 11$, \\
\hline Cell volume\| & 11 & $0.247 \pm 0.012$ & $\mathrm{SL}(<0.01)$ & all low & 0 \\
\hline
\end{tabular}

* Patient assays L2, 5, 9, 10, 10a, 11, 12, 13, 15, 16, 18.

$\dagger$ See footnote* to Table I.

$\ddagger$ Taken from reference (1).

$\$$ Standard deviation of the mean. Values in brackets are approximate.

|| Volume of one billion leukocytes. 
TABLE VI

Concentration of unbound amino acids in leukocytes of treated chronic lymphocytic leukemic patients *

\begin{tabular}{|c|c|c|c|c|c|c|}
\hline & \multicolumn{4}{|c|}{ Chlorambucil } & \multirow{2}{*}{$\underset{\text { L14 }}{\text { TEM }}$} & \multirow{2}{*}{$\begin{array}{l}\text { Nitrogen } \\
\text { mustard } \\
\text { L17 }\end{array}$} \\
\hline & $\mathrm{L}_{1}$ & L6 & L3 & L4 & & \\
\hline Alanine & 2,030 & $7,200 \uparrow$ & $330 \downarrow$ & 3,550 & 1,240 & 2,690 \\
\hline Arginine & 1,000 & 800 & $<100$ & 200 & $<100$ & 100 \\
\hline Glutamic acid & 3,100 & 4,230 & $750 \downarrow$ & 3,900 & $5,200 \uparrow$ & 4,290 \\
\hline Glutamine & 2,200 & 2,530 & 1,500 & 1,100 & 1,100 & 2,550 \\
\hline Histidine & $<200 \downarrow$ & $3,660 \uparrow$ & $<200 \downarrow$ & $90 \downarrow$ & 620 & 950 \\
\hline Lysine & 2,900 & $5,950 \uparrow$ & $<500$ & 610 & $410 \downarrow$ & 1,680 \\
\hline Methionine & 660 & & $<100$ & & & 310 \\
\hline Ornithine & $<400 \downarrow$ & $16,000 \uparrow$ & $<200 \downarrow$ & $<200 \downarrow$ & $330 \downarrow$ & $700 \downarrow$ \\
\hline Phenylalanine & 700 & $<600$ & 150 & $<300$ & 950 & 2,200 \\
\hline Proline & 730 & $2,800 \uparrow$ & $<200 \downarrow$ & 530 & 870 & $1,630 \uparrow$ \\
\hline Threonine & $<700 \downarrow$ & $6,400 \uparrow$ & $970 \downarrow$ & $735 \downarrow$ & 1,040 & 1,570 \\
\hline Tryptophan & 290 & 600 & $<50$ & 60 & 150 & 550 \\
\hline Tyrosine & 880 & 2,700 & 180 & 210 & 400 & 900 \\
\hline Valine & 1,460 & $2,800 \uparrow$ & 430 & 430 & 820 & 1,230 \\
\hline Ethanolamine & $<300$ & $<600$ & $1,950 \uparrow$ & $<300$ & $<200$ & $<200$ \\
\hline Leucine plus isoleucine & & $6,750 \uparrow$ & $330 \downarrow$ & $590 \downarrow$ & 1,000 & 1,290 \\
\hline Serine plus glycine & 8,400 & $71,000 \uparrow$ & 2,700 & 4,300 & $87,000 \uparrow$ & 9,000 \\
\hline Taurine & 21,000 & 49,000 & 10,600 & 19,700 & 22,000 & 13,600 \\
\hline O-phosphoethanolamine & & 3,400 & & 4,700 & $5,580 \uparrow$ & $12,400 \uparrow$ \\
\hline Cell volume & $0.37 \downarrow$ & $0.31 \downarrow$ & $0.31 \downarrow$ & $0.27 \downarrow$ & $0.33 \downarrow$ & $0.28 \downarrow$ \\
\hline Cell count $\ddagger$ & 9.3 & 5.0 & 67.0 & 56.0 & 9.3 & 57.0 \\
\hline
\end{tabular}

* The values are expressed as micromoles per kilogram water. The symbol $\downarrow$ following the number in the column indicates that the value is at least $2 \mathrm{SD}$ below the normal mean. The symbol $\uparrow$ following the number indicates that the value is at least $2 \mathrm{SD}$ above the normal mean (1).

$\dagger$ Volume of one billion leukocytes.

$\ddagger$ Counts per $\mathrm{mm}^{3} \times 10^{-3}$ of whole blood.

dichloro-N-methyldiethylamine, Merck). The assays of these patients are listed in Table VI. As previously noted, the high concentrations of O-phosphoethanolamine typical of the untreated chronic lymphocytic leukemias were not uniformly found in this group of patients. Furthermore, glutamic acid was not as high in the leukocytes of this group as in other leukemic patients. Other amino acids showed large variations in concentration which appeared to be influenced by the type of treatment and period of time after treatment. A discussion of these effects in each of these patients follows.

In the leukocytes of two patients (assays L1 and L6) shortly after treatment with Chlorambucil, concentrations of amino acids were considerably higher than those found in untreated patients. Thus, in assay L1, from Patient H.B. on the tenth day after the start of a three week course of Chlorambucil, amino acid concentrations were approximately 40 per cent higher than those of untreated chronic lymphocytic patients. With the exception of histidine, ornithine, and threonine, whose concentrations were low, the unbound amino acid concentrations for this assay were comparable with the concentrations in leukocytes of normal subjects. In analysis L6, taken from Patient A.J.R. on the nineteenth day after completion of a three week course of Chloroambucil, a very marked increase in the unbound amino acid concentrations was observed. The values were much higher than the concentrations which had been found for untreated chronic lymphocytic leukemics and were higher than $2 \mathrm{SD}$ from the means from normal leukocytes in all substances except for glutamic acid, glutamine, taurine and O-phosphoethanolamine. The white cell counts of both of these patients had been brought down by the treatment from high to normal levels. The volume of the cells was unchanged by the chemotherapy. The differential count for Patient H.B. showed 87 per cent lymphocytes and 9 per cent polymorphonuclear neutrophils. The differential count for Patient A.J.R. in analysis L6, however, had been changed from predominantly lymphocytes before treatment to a differential count of 70 per cent polymorphonuclear neutrophils, 10 per cent lymphocytes and 6 per cent myelocytes after treatment. The large change in unbound amino acid concentrations therefore accompanied a 
change in the proportion of cell types in this patient. This increase could not be explained solely by a change in cell type, since other patients with cell types similar to those in assay L6 did not show elevated amino acid concentrations.

Two analyses from one patient were taken 44 days (assay L3) and 75 days (assay L4) after completion of different series of Chloroambucil treatment (see Table VI). The unbound amino acid concentrations found in each were either as low as or lower than the concentrations found in untreated patients. Presumably the critical stage of elevated amino acid concentrations following treatment had passed. However, the response of this patient to Chlorambucil had not been satisfactory as far as white count depression was concerned. Analysis L3 was unique in that it showed the lowest unbound amino acid concentration ever found. The average concentration was approximately one-fourth that found in normal leukocytes. Glutamine was normal and ethanolamine was elevated. The unbound amino acid analyses of the urine for this assay were also very low. The white count was 67.000 per $\mathrm{mm}^{3}$ for analysis L3 and 56,000 per $\mathrm{mm}^{3}$ for analysis L4. The cell type in both analyses was essentially all lymphocytic.

One assay (L14) was conducted on a patient on the twelfth day following completion of treatment with TEM, and another assay (L17) was conducted on a patient who had had treatment with nitrogen mustard on the eighteenth, seventeenth and fourth days prior to the assay. The results of these assays are listed in Table VI. $\mathrm{O}$-phosphoethanolamine was elevated in the leukocytes of both of these patients, glutamic acid was elevated in one. Other amino acid concentrations were irregular but usually higher than those found in untreated chronic lymphocytic leukemic patients. A different response to treatment by Chlorambucil and these two compounds in relation to O-phosphoethanolamine and glutamic acid reduction is thus implied although the number of subjects involved is very small.

d) Chronic lymphocytic leukemia after X-ray treatment. A patient with chronic lymphocytic leukemia and large deposits of lymphosarcoma had two tests conducted in association with $\mathrm{X}$-ray treatment and a third test conducted well after the period of X-ray treatment; Table VII lists the leukocyte and urine values for these analyses. The first analysis was made on the day after the first exposure to $20 \mathrm{r}$ units of total body radiation. Alanine, glutamic acid, taurine and O-phosphoethanolamine concentrations in the leukocytes were elevated 5-, 20-, 4- and 20-fold, respectively, above the mean of normal subjects as well as above that of the untreated lymphocytic leukemic patients. Several of the other amino acids were moderately elevated, whereas only histidine and ornithine were low. After completion of the first course of X-ray treatment, the white cell counts of the patient were reduced from 487,000 to 9,500 per $\mathrm{mm}^{3}$ in three months, but the masses of lymphosarcoma in various areas of the lymph nodes were not much reduced. A second course of X-ray consisting of $40 \mathrm{r}$ units per treatment to large areas of the body, but not total body radiation, was given on the sixth, fourth, third and second days prior to the second analysis. Some reduction in the quantity of the amino acids in very high concentrations was noted when compared with the earlier analysis. However, alanine, glutamic acid, leucine plus isoleucine, lysine, threonine, and serine plus glycine were elevated approximately twofold above the normal range and O-phosphoethanolamine was elevated eightfold. On the third analysis, 135 days following the second course of $\mathrm{X}$-ray treatment, and with no intervening treatment of any kind except transfusions, the leukocyte levels had returned to the state of the typical untreated chronic lymphocytic leukemia. The elevated amino acid concentrations in the leukocytes following X-ray treatment were not influenced by the magnitude of the white cell count as these differed enormously: 490,000, 9,500 and 22,000 per $\mathrm{mm}^{3}$ for bloods from analyses L7. L8 and L9, respectively. No changes occurred in cell type following X-ray (all lymphocytes). The packed-cell volumes of the leukocytes in these assays were not significantly larger than the packed-cell volumes of lymphocytic leukemic patients who had not had $\mathrm{X}$-ray irradiation. This does not agree with the increases in cell volumes observed by others following in vivo irradiation of Yoshida sarcoma cells in rats (10) or Ehrlich carcinoma cells in mice (11).

Except for an increased concentration of urea 
TABLE VII

Relationship between the unbound amino acid concentrations in the leukocytes and their excretion rates in the urine of a patient following $X$-ray treatments *

\begin{tabular}{|c|c|c|c|c|c|c|}
\hline & \multicolumn{2}{|c|}{$\begin{array}{c}L 7 \\
24 \text { hrs after X-ray }\end{array}$} & \multicolumn{2}{|c|}{$\begin{array}{c}\text { L8 } \\
48 \text { hrs after X-ray }\end{array}$} & \multicolumn{2}{|c|}{$\begin{array}{l}\text { L9 } \\
135 \text { days after } \mathrm{X} \text {-ray }\end{array}$} \\
\hline & Leukocytes & Urine & Leukocytes & Urine & Leukocytes & Urine \\
\hline \multirow{20}{*}{$\begin{array}{l}\text { Alanine } \\
\text { Arginine } \\
\text { Glutamic acid } \\
\text { Glutamine } \\
\text { Histidine } \\
\text { Lysine } \\
\text { Methionine } \\
\text { Ornithine } \\
\text { Phenylalanine } \\
\text { Proline } \\
\text { Threonine } \\
\text { Tryptophan } \\
\text { Tyrosine } \\
\text { Valine } \\
\text { Ethanolamine } \\
\text { Leucine plus isoleucine } \\
\text { Serine plus glycine } \\
\text { Taurine } \\
\text { Urea } \\
\text { O-phosphoethanolanine } \\
\text { Cell volume } \\
\text { Cell count }\end{array}$} & $13,500 \uparrow$ & \multirow[t]{2}{*}{11.0} & $8,500 \uparrow$ & \multirow[t]{2}{*}{14.6} & $\begin{array}{l}3,760 \\
00\end{array}$ & \multirow[t]{2}{*}{10.0} \\
\hline & $65,000 \uparrow$ & & $8,500 \uparrow$ & & $6,570 \uparrow$ & \\
\hline & $7,100 \uparrow$ & \multirow{3}{*}{$\begin{array}{l}66.0 \uparrow \\
40.0\end{array}$} & 2,580 & \multirow{4}{*}{$\begin{array}{l}28.6 \\
68.0 \\
12.7\end{array}$} & 1,570 & \multirow{4}{*}{$\begin{array}{r}15.0 \\
35.0 \\
3.7\end{array}$} \\
\hline & 200 & & $1,600 \uparrow$ & & $240 \downarrow$ & \\
\hline & $5,450 \uparrow$ & & $5,900 \uparrow$ & & 1,410 & \\
\hline & 500 & . & $\begin{array}{r}100 \\
2850\end{array}$ & & & \\
\hline & $\begin{array}{l}500 \downarrow \\
930\end{array}$ & 5.0 & $\begin{array}{l}2,850 \\
1,510 \uparrow\end{array}$ & \multirow[t]{2}{*}{8.3} & $\begin{array}{l}940 \\
300\end{array}$ & \multirow{2}{*}{2.1} \\
\hline & 1,440 & & $2,000 \uparrow$ & & 970 & \\
\hline & $4,850 \uparrow$ & 16.6 & 5,830 & \multirow[t]{2}{*}{11.0} & 1,290 & \multirow{2}{*}{$\begin{array}{l}9.0 \\
22\end{array}$} \\
\hline & 250 & & 460 & & 100 & \\
\hline & 1,000 & 6.4 & $1,050 \uparrow$ & \multirow{2}{*}{$\begin{array}{l}4.1 \\
3.6\end{array}$} & 450 & \multirow{2}{*}{$\begin{array}{l}2.8 \\
1.0\end{array}$} \\
\hline & 1,600 & 4.8 & $3,200 \uparrow$ & & 940 & \\
\hline & & $68.0 \uparrow$ & 840 & 17.0 & $890 \uparrow$ & 2.7 \\
\hline & 2,400 & \multirow{7}{*}{$\begin{array}{c}56.0 \\
220.0 \uparrow \\
21,400\end{array}$} & $\mathbf{5 , 2 5 0}$ & & 1,100 & \multirow{7}{*}{$\begin{array}{r}35.0 \\
28.0 \\
11,300\end{array}$} \\
\hline & 20,200 & & $46,000 \uparrow$ & 97.0 & 8,900 & \\
\hline & $115,000 \uparrow$ & & 21,600 & $116.0 \uparrow$ & 23,600 & \\
\hline & & & & 15,400 & & \\
\hline & $63,000 \uparrow$ & & $23,000 \uparrow$ & & $6,400 \uparrow$ & \\
\hline & $0.31 \downarrow$ & & $0.31 \downarrow$ & & $0.28 \downarrow$ & \\
\hline & 490.0 & & 9.5 & & 22.0 & \\
\hline
\end{tabular}

* Leukocyte values are expressed as micromoles per kilogram water. The urine excretion rates are expressed as micromoles excreted per hour. The symbol $\downarrow$ following a leukocyte value indicates that it is at least 2 SD below the normal mean; the symbol $\uparrow$ following a value indicates that it is at least 2 SD above the normal mean (1). For the urines, these symbols indicate that the values are 50 per cent less than the lowest normal value or 200 per cent greater than the highest normal value (5).

$\dagger$ Volume of one billion leukocytes.

$\ddagger$ Counts per $\mathrm{mm}^{3} \times 10^{-3}$ of whole blood.

in the plasma and erythrocytes, and an increased concentration of glutamic acid in the erythrocytes, irradiation did not affect the unbound amino acids in the blood compartments other than the leukocytes.

High concentrations of phenylalanine and ornithine were observed in the plasma and erythrocytes of this patient (S.G.) without regard to the time the assay was conducted after irradiation, and therefore these elevated values do not appear to be associated with radiation exposure.

Katz and Hasterlik (12) found, in a study of individuals accidentally exposed to varying amounts of total body irradiation, that while aminoaciduria was evident 12 hours after exposure the peak excretion was not reached until the sixth day. Kay, Early and Entenman (13), however, had observed a peak excretion of taurine and urea in rats five hours after irradiation. In the curent study, in which exposure to irradiation had occurred approximately 24 hours prior to assay L7 and approximately 48 hours prior to assay L8, taurine excretion rates were very high in both assays, and urea, glutamine, and ethanolamine excretion rates were moderately high. Of considerable interest in this study was the correlation between the high excretion rates and high concentrations of some compounds in the plasma, erythrocytes and leukocytes following the X-ray exposure. Thus the high excretion rate of taurine corresponded to high concentrations of taurine in the leukocytes. High excretion rates of glutamine corresponded to high concentrations of glutamic acid (the precursor for the glutamine excreted in the urine) in the leukocytes and erythrocytes. High excretion rates of ethanolamine in assay L7 corresponded to a very high concentration of O-phosphoethanolamine in the leukocytes (O-phosphoethanolamine is presumably hydrolyzed to give ethanolamine). Finally, high excretions of urea corresponded to high concentrations of urea in the plasma and erythrocytes. 
Excretion of amino acids in the urines of leukemic patients

The means and ranges of the excretion rates for 29 of the leukemic patients are given in Table VIII. Assays L7 and L8 were omitted from this table since some of their values were very high and they have been presented separately in Table VII ; assays L12 and L15 were lost. Columns 5 and 6 of this table list the patients with very low or very high excretions for particular substances. The mean excretion rates of the patients are reasonably close to those of normal subjects. Several substances showed occasional large fluctuations in the patients' excretion. Taurine was high in two analyses, L4 at $80 \mu$ moles per hour and M2 at $310 \mu$ moles per hour. The patient with assay L4 was on Day 75 following a course of Chlorambucil and on the third day after the start of a new course of Chlorambucil, but was not otherwise unusual. The patient with assay $\mathrm{M} 2$, in addition to extremely high taurine excretion also had a moderately high excretion rate for many other substances. This patient, in addition to monocytic leukemia, had an acute rectal abscess which may have influenced the amino acid excretion pattern. Several of the patients had low tau- rine excretion rates which did not appear to be associated with any particular form of leukemia or treatment. In the analysis of one patient (assay L10a) serine plus glycine was excreted at the very high level of $390 \mu$ moles per hour with somewhat moderate increases in excretion of the other amino acids. An unusual feature of this patient. was that in an analysis 74 days earlier, and with no apparent intervening change having taken place in the patient's condition, a normal excretion rate for all substances was found (assay L10). Proline and valine, which were usually not found in the urines of normal subjects, were excreted in increased amounts by some of the patients.

A rather unusual finding was the low excretion rate for ethanolamine in six urines of patients with chronic lymphocytic leukemia. Ethanolamine was elevated in the plasma and erythrocytes of some of the patients. However, except for an analysis following $\mathrm{X}$-ray exposure, ethanolamine was never excreted by the patients in amounts greater than those excreted by normal subjects. This suggests that ethanolamine is being utilized in some manner, perhaps associated with O-phosphoethanolamine formation, rather than being excreted. The possibility of the excretion of etha-

TABLE VIII

Rate of excretion of unbound amino acids in urines of leukemic patients *

\begin{tabular}{|c|c|c|c|c|c|}
\hline & $\begin{array}{l}\text { No. of } \\
\text { analyses }\end{array}$ & Mean & Range & $\begin{array}{l}\text { Analyses with values } \\
\text { less than } 50 \% \text { of } \\
\text { lowest normal valuet }\end{array}$ & $\begin{array}{c}\text { Analyses with } \\
\text { values higher } \\
\text { than } 200 \% \text { of } \\
\text { highest normal } \\
\text { valuet }\end{array}$ \\
\hline Alanine & 29 & 7.8 & $1.8-18.5$ & 0 & 0 \\
\hline Arginine & 11 & $<0.5$ & & 0 & 0 \\
\hline Glutamine & 27 & 13.8 & $1.8-30.0$ & G13, L3 & 0 \\
\hline Histidine & 29 & 28.1 & $5.0-79.0$ & 0 & 0 \\
\hline Lysine & 26 & 7.0 & $2.1-25.0$ & 0 & 0 \\
\hline Methionine & 29 & $<1.0$ & & 0 & 0 \\
\hline Ornithine & 19 & $<2.0$ & & 0 & 0 \\
\hline Phenylalanine & 29 & $<1.6$ & $<1.0-4.4$ & 0 & 0 \\
\hline Proline & 29 & $<1.0$ & $<0.3-3.9$ & 0 & $\mathrm{G} 4,8, \mathrm{~L} 3$ \\
\hline Threonine & 26 & 5.7 & $2.1-13.0$ & 0 & 0 \\
\hline Tryptophan & 29 & $<1.9$ & $<0.3-5.4$ & 0 & 0 \\
\hline Tyrosine & 29 & $<2.9$ & $<1.0-8.0$ & G13 & 0 \\
\hline Valine & 29 & $<1.8$ & $<1.0-8.3$ & 0 & $\mathrm{M} 2, \mathrm{~L} 4,10 \mathrm{a}, 14$ \\
\hline Ethanolamine & 27 & $<12.9$ & $<1.0-44.0$ & $\mathrm{~L} 1,6,9,13,16,17$ & 0 \\
\hline Guanidoacetic acid & 11 & $<10.2$ & $<1.0-24.0$ & G13 & 0 \\
\hline Leucine plus isoleucine & 29 & $<2.3$ & $<1.0-4.0$ & 0 & 0 \\
\hline Serine plus glycine & 29 & 55.0 & $<8.0-390.0$ & $\mathrm{G} 13$ & L10a \\
\hline Taurine & 29 & 31.5 & $2.7-310.0$ & $\mathrm{G} 4, \mathrm{~L} 1,10,16$ & $\mathrm{M} 2, \mathrm{~L} 4$ \\
\hline Urea & 28 & 10,000 & $2,900-19,400$ & 0 & 0 \\
\hline$\beta$-Amino isobutyric acid & 2 & 17.0 & $14 \quad 20$ & & $\mathrm{~L} 1,3$ \\
\hline
\end{tabular}

* Urines of assays L7, L8, L12, and L15 are excluded from these averages. Values are expressed as micromoles excreted per hour.

$\dagger$ The ranges for the normal values are taken from reference (5). 
nolamine in a complex form was not investigated. In any event, the results of this study strongly support a disturbed ethanolamine and O-phosphoethanolamine metabolism in the leukemic patients.

$\beta$-Amino isobutyric acid, which was found infrequently in our analyses of normal subjects (1), was found in moderate amounts in urine assays L1 and L3; both patients had had treatment with Chlorambucil. In some of our assays an unidentified ninhydrin-positive substance in very high concentration interfered with the estimation of $\beta$-amino isobutyric acid. Fink, Henderson and Fink (14) first reported the presence of $\beta$-amino isobutyric acid in urine. These workers noted that its concentration was occasionally very high in cancer patients and apparently related to the neoplastic process. Awapara (15) found $\beta$-amino isobutyric acid to be excreted in large amounts in the urines of leukemic patients treated with nitrogen mustard, provided the analysis coincided with a particular time interval after the treatment.

\section{DISCUSSION}

In all four of the body compartments of leukemic patients (that is, plasma, erythrocytes, leukocytes, and urine) differences from normal subjects have been found to exist. These are reported in some detail in the preceding section. For brevity and easy reference the principal findings in each compartment are also tabulated in Table IX. It is important to recognize that while some changes were reflected simultaneously in two compartments, e.g., increase in glutamic acid and proline in both erythrocytes and leukocytes of the leukemic patients, other changes occurred in only one specific compartment, e.g., increase in serine plus glycine in the erythrocytes, increases of ornithine in the erythrocytes, or decreases of ornithine in the leukocytes. By virtue of these different responses, it must be concluded that in leukemia each of the fluid compartments is affected in a different manner.

One may speculate at some length on the significance of the complex changes observed in the leukemic patients. One of the most striking, and certainly one which appears to be common to the neoplastic process, since it is also found in other malignancies $(7,8)$, is the elevated cell glutamic acid concentration. In the present study high glutamic acid was observed not only in the leukocytes but also in the erythrocytes. The cause of its elevation is not clear; it may be due to an alteration in metabolism of the cancer cells, such as in the citric acid cycle where $\alpha$-ketoglutarate

TABLE IX

Tabulation of the principal differences in concentrations of unbound amino acids and other substances found in the study of the leukemic patients when compared with normal subjects*

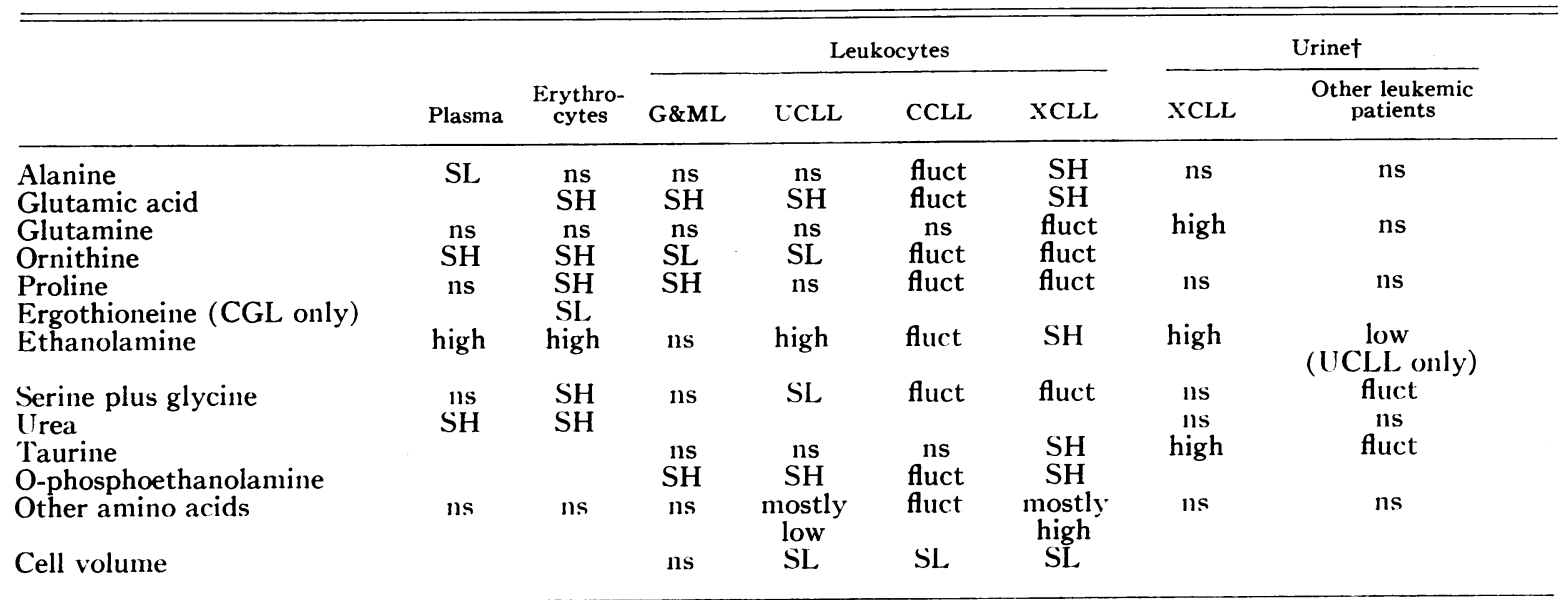

* G\&ML = granulocytic and monocytic leukemic patients. UCLL = chronic lymphocytic leukemic patients untreated by chemotherapy or X-ray irradiation. CCLL = chronic lymphocytic leukemic patients treated with chemotherapeutic agents. XCLL $=$ a chronic lymphocytic leukemic patient after X-ray irradiation. $C G L=$ chronic granulocytic leukemia. $\mathrm{SH}=$ significantly high. $\mathrm{SL}=$ significantly low; $\mathrm{ns}=$ not significantly different; fluct $=$ fluctuated.

$\dagger$ The other amino acids include $\alpha$-amino- $n$-butyric acid, arginine, histidine, lysine, methionine, phenylalanine, threonine, tyrosine, valine, leucine plus isoleucine, serine plus glycine, and ergothioneine (excluding chronic granulocytic leukemia). 
is a congener of glutamic acid or in transamidation where glutamic acid is involved, or it may be the result of some unknown defect.

Equally less well understood in its role is the increase of O-phosphoethanolamine in the leukocytes. This substance has also been reported elevated in malignant tissues by others (6). Because it is to a large extent normally fixed in the structure of the cell lipid, the increase may be the result of more rapid turnover of the leukemic as compared with normal cells. The increase in O-phosphoethanolamine concentration in the leukemic white cells is so marked that its use for the diagnosis of leukemia may be feasible. It is of additional interest that both glutamic acid and O-phosphoethanolamine are reduced in concentration in the remission following treatment with Chlorambucil.

A number of changes in concentrations of other substances were noted. Certainly the marked reduction of ergothioneine in the chronic granulocytic leukemic patients should be further investigated. Also, the finding of increased concentrations of amino acids in the leukocytes following extensive body radiation is of much interest. In the latter investigations only small changes were observed in the plasma and erythrocytes, which suggests that the leukocytes may be the more susceptible to radiation damage.

\section{SUMMARY}

Interrelationships among the amino acid concentrations in the blood cells, plasma and urine of patients with chronic granulocytic, chronic lymphocytic, acute granulocytic, subacute granulocytic and monocytic leukemia have been studied. When compared with normal subjects the following significant differences were observed.

1. Findings common to all the leukemic patients: $a$ ) In the plasma, ornithine, ethanolamine and urea were high, alanine was low. $b$ ) In the erythrocytes, ornithine, proline, ethanolamine, serine plus glycine, and urea were high. c) In the leukocytes, O-phosphoethanolamine, glutamic acid and proline were high, ornithine was low. Proline was high in the leukocytes of the chronic lymphocytic leukemic patients only when compared relative to the other amino acids. d) Ornithine and urea concentrations were found to be related, that is, increased and decreased together, in the plasma of leukemic patients with adequate kidney function. $e$ ) Ornithine concentrations increased in the plasma and erythrocytes but decreased in the leukocytes of the leukemic patients.

2 . Findings common to certain types of leukemia or treatment of leukemia: a) $\beta$-Amino isobutyric acid, which was not found in normal plasma, was found in two plasmas after the patients had been treated with Chlorambucil. $\left.{ }^{1} \quad b\right)$ Ergothioneine was decreased (average, 75 per cent) in the erythrocytes of chronic granulocytic leukemic patients. c) Ethanolamine was high, alanine, proline, tyrosine, and probably arginine were in the normal range; all other substances, except glutamic acid and O-phosphoethanolamine mentioned above, were low in the leukocytes of untreated chronic lymphocytic leukemic patients. $d$ ) In the leukocytes of two chronic lymphocytic leukemic patients, one 10 days after the start of Chlorambucil treatment, the other 19 days after completion of a series of Chlorambucil treatments, most of the amino acid concentrations were irregularly increased. In the leukocytes of another chronic lymphocytic leukemic patient, on Day 44 and Day 75 following completion of treatment by Chlorambucil, most of the amino acid concentrations were very low. In both of these groups of patients there was a tendency for the concentrations of glutamic acid and O-phosphoethanolamine to decrease from very high values (characteristic of leukemia) to values approaching those of normal subjects. $e$ ) In the leukocytes of a chronic lymphocytic leukemic patient 12 days after treatment with $\mathrm{TEM}^{2}$ and a similar patient on Days 18, 17 and 4 after treatment with nitrogen mustard ${ }^{3}$ concentrations of amino acids were irregular but somewhat elevated. f) In the leukocytes of a chronic lymphocytic leukemic patient 24 hours and 48 hours after X-ray irradiation, most of the amino acids were highly elevated. A high excretion rate of urea, glutamine, taurine and ethanolamine in the urine of this patient correlated well with high concentrations of these substances or their precursors in either the plasma or the blood cells. g) In the urine of some of the untreated chronic lymphocytic leukemic patients ethanolamine was excreted in low amounts. Irregular excretion rates of a few other compounds were observed in urines of leukemic patients but without 
regard to the type of leukemia. $h$ ) Arginine was lower in the plasma of chronic granulocytic leukemic patients than in chronic lymphocytic leukemic patients. i) Treatment of granulocytic leukemic patients with Myleran (tetra-ethylenemethane sulfonic acid), 6-mercaptopurine, Meticorten, testosterone or spray X-ray to the spleen five days before the analyses caused no recognizable changes in amino acid concentrations in the leukocytes of this group of patients.

\section{ACKNOWLEDGMENT}

We are very grateful to Drs. J. L. Tullis, New England Deaconess Hospital; J. H. Katz, Veterans Administration Hospital; W. C. Moloney and L. N. Pernokas, Boston City Hospital; and F. H. Gardner, Peter Bent Brigham Hospital, (all in Boston, Mass.), for patients to conduct this study. We wish to thank Dr. J. L. Oncley for his suggestions and interest in our work. Appreciation is also expressed to Mr. J. VanMarcke, Mr. G. J. Neville and Miss B. Steele for performance of the assays.

\section{CASE HISTORIES}

\section{Terms and abbreviations}

The letter and number following the patients' initials are the sex and age. Prior treatments are those that were given for leukemia four months or more before the assay. Recent treatments are those that were given for leukemia less than four months before the assay. Hematology. The leukocyte counts per $\mathrm{mm}^{3}$ blood (WBC) were taken the day of the assay. Hematocrits (Hct.), grams hemoglobin per $100 \mathrm{ml}$ blood ( $\mathrm{Hg}$.), and platelet counts per $\mathrm{mm}^{3}$ blood (Plat. C.) were taken the day of the assay or several days before.

Aristocort $($ Lederle $)=$ triamcinolone. Chlorambucil (Burroughs Wellcome) $=4$ - $[\mathrm{p}-$ bis (2chloroethyl)amino phenyl] butyric acid. Meticorten (Schering) = prednisone. Myleran (Burroughs Wellcome) $=$ tetra-ethylenemethane sulfonic acid. Nitrogen mustard (Merck Sharp \& Dohme) $=2,2^{\prime}$-dichloro-N-methyldiethylamine hydrochloride. Orinase (Upjohn) 1-butyl-3ptolysulfonyl-urea. TEM (Lederle) =2,4,6-triethyleneimino-s-triazine.

Chronic lymphatic leukemia

L1: H.B. M 54 Complication, diabetes mellitus, insulin treatment

Prior treatment, X-ray

$1953-1956$

Recent treatment, Chlorambucil $6 \mathrm{mg} /$ day

Red cell transfusion $500 \mathrm{ml}$

Hematology, WBC 11,600; Hg. 8.3 g Plat. C., 150,000

Assay no. 1

L2: T.McC. M 75 Complication, carcinoma of skin

Prior treatment, none

Recent treatment, Chlorambucil, $10 \mathrm{mg} /$ day

Hematology, WBC 52,000; Hg. 11.9 g Plat. C., 80,000

Assay no. 1

L3: A.R. F 67 Complication, diabetes mellitus, insulin treatment

Prior treatment, X-ray

TEM $2.5 \mathrm{mg} 3$ times/week

Chlorambucil, $6 \mathrm{mg} /$ day at intervals

Recent treatment, Chlorambucil, $6 \mathrm{mg} / \mathrm{day}$

Chlorambucil, $6 \mathrm{mg} /$ day

Hematology, WBC, 95,000; Hg. 14.5 g Plat. C., 150,000

Assay no. 1

L4: A.R. See above

Prior treatment, see above

Recent treatment, Chlorambucil $6 \mathrm{mg} /$ day

Chlorambucil $6 \mathrm{mg} /$ day

Hematology, WBC 83,000

Assay no. 2

$4 / 3-4 / 24 / 58$

$7 / 7 / 58$

L5: A.J.R. F 67 Complication, diabetes mellitus, insulin treatment

Treatment, none

Hematology, WBC 35,500; Hg. 13.6 g

Assay no. 1
$5 / 21-5 / 29 / 58$

$5 / 29 / 58$

9/21-10/1/57

$9 / 30 / 57$

$10 / 1 / 57$

1955-1956

$4 / 6-6 / 2 / 56$

1956

6/10-7/9/57

$10 / 16-11 / 7 / 57$

$10 / 21 / 57$ 
L6: A.J.R. See above

Recent treatment, Chlorambucil, $8 \mathrm{mg} /$ day

$5 / 27-6 / 18 / 58$

Hematology, WBC 5,000

Assay no. 2

L7: T.S. M 65 Complication, lymphosarcoma of axilla and mediastinum

Recent treatment, 10 daily treatments of spray X-ray, each $20 \mathrm{r}$

Red cell transfusion, $500 \mathrm{ml}$

$12 / 12-12 / 23 / 57$

Hematology, WBC 487,000, Hg. $10.0 \mathrm{~g}$

Assay no. 1

$12 / 13 / 57$

L8: T.S. See above

Recent treatment, $4 \mathrm{X}$-ray treatments to sarcoma, $40 \mathrm{r}$ each

Red cell transfusions $500 \mathrm{ml}$

Testosterone $100 \mathrm{mg} 3$ times/week

Hematology, WBC 9,500; Hg. 9.7 g Plat. C., 13,000

Assay no. 2

$3 / 8,3 / 10,3 / 11$ and $3 / 12 / 58$

$1 / 12$ and $2 / 12 / 58$

$2 / 12-5 / 23 / 58$

$3 / 14 / 58$

I.9: T.S. See above

Recent treatment, red cell transfusions $1500 \mathrm{ml}$

Testosterone, $50 \mathrm{mg} 3$ times/week

Hematology, WBC 22,000

Assay no. 3

$5 / 23-7 / 28 / 58$

$7 / 28 / 58$

L10: C.L. M 63 Complication, cerebral artery occlusion

Treatment, none

Hematology, WBC 19,000; Hg. $14.0 \mathrm{~g}$

Assay no. 1

$10 / 30 / 58$

L11 : A.L. M 50 Complication, diabetes mellitus, Orinase treatment Treatment, none

Hematology, WBC 22,600; Hg. 12.4 g Plat. C., 200,000

Assay no. 1

$10 / 24 / 58$

L12: T.K. M 73 Complication, bronchopneumonia, antibiotic treatment

Treatment, Whole blood transfusion $1000 \mathrm{ml}$

Hematology, WBC 150,000; Hg. $8.3 \mathrm{~g}$

Assay no. 1

$12 / 13 / 58$

$12 / 19 / 58$

L13: C.V. M 63 Complication, pneumococcal pneumonia, penicillin treatment

Treatment, none

Hematology, WBC 60,000 ; Hct. 44

Assay no. 1

$2 / 6 / 59$

L14: F.C. M 44

Prior treatment, TEM intermittent

Recent treatment, TEM $2.5 \mathrm{mg} /$ day

Hematology, WBC 9,300; Hct. 41.5

$1951-1959$

Assay no. 1

$1 / 15-1 / 29 / 59$

$2 / 10 / 59$

L15: M.P. F 79 Complications, staphylococcus pneumonia and arteriosclerotic heart disease, penicillin and digitalis treatment

Prior treatment, Chlorambucil $12 \mathrm{mg} /$ day for 30 days

$\mathrm{X}$-ray to mediastinum

$1 / 59$

Recent, none

Hematology, WBC 12,500; Hct. 31

Assay no. 1 
L16: L.M. M 67

Treatment, none

Hematology, WBC 139,500; Hct. 28

Assay no. 1

$4 / 13 / 59$

L17 : L.M. See above

Recent treatment, whole blood transfusion $500 \mathrm{ml}$

$4 / 13 / 59$

Nitrogen mustard $17 \mathrm{mg}$

Nitrogen mustard $10 \mathrm{mg}$

$4 / 13$ and $4 / 14 / 59$
$4 / 28 / 59$

Hematology, WBC 57,000; Hct. 35

Assay no. 2

$4 / 13$ and $4 / 14 / 59$
$4 / 28 / 59$

$5 / 1 / 59$

L18: L.S. F 84

Recent treatment, whole blood transfusion $2500 \mathrm{ml}$ Chlorambucil $10 \mathrm{mg} /$ day

Cortisone $20 \mathrm{mg} / 6 \mathrm{hrs}$

Hematology, WBC 46,000; Hct. 19

Assay no. 1

Granulocytic leukemia

G1: G.B. F 28 Type of leukemia: chronic

Prior treatment, spray X-ray

Recent treatment, Myleran, $4 \mathrm{mg} / \mathrm{day}$

Hematology, WBC 236,000; Hg. 13.4 g Plat. C., 360,000

Assay no. 1

$5 / 5-5 / 8 / 59$

$5 / 6-5 / 27 / 59$

$5 / 6-5 / 27 / 59$

$5 / 8 / 59$

G2: G.B. See above

Recent treatment, Myleran $2 \mathrm{mg} /$ day

Hematology, WBC 9,500; Hg. 13.5 g Plat. C., very high

Assay no. 2

1956

$3 / 31-4 / 19 / 58$

$4 / 2 / 58$

$7 / 30-9 / 17 / 58$

$9 / 17 / 58$

G3: V.M. F 66 Type of leukemia: chronic

Prior treatment, spray X-ray

1956 and 1957

Recent treatment, none

Hematology, WBC 19,500; Hg. 10.5 g

Assay no. 1

$9 / 30 / 57$

G4: J.R. M 45 Type of leukemia: chronic

Prior treatment, spray X-ray

Recent treatment, none

Hematology, WBC 56,500 ; Hg. 14.5 g Plat. C., 260,000

Assay no. 1

$11 / 14 / 57$

G5 : E.G. F 14 Type of leukemia : acute

Complication, leukemic infiltration of lungs

Prior treatment, multiple whole bloods

6-Mercaptopurine $25 \mathrm{mg} /$ day

Aristocort $12 \mathrm{mg} / \mathrm{day}$

Recent treatment, multiple whole blood transfusions

6-Mercaptopurine $25 \mathrm{mg} /$ day

Meticorten $25 \mathrm{mg} /$ day

Hematology, WBC 7,900; Hg. 10.2 g Plat. C., 20,000

Assay no. 1

1956 and 1957

G6: P.R. M 68 Type of leukemia: acute

Complication, leukemic infiltration of lungs

Recent treatment, whole blood transfusions 2.0 or 2.51 per mo

6-Mercaptopurine $50 \mathrm{mg} /$ day

Meticorten $5 \mathrm{mg} /$ day

Testosterone $100 \mathrm{mg} /$ day

$\mathrm{X}$-ray to lungs $50 \mathrm{r}$

Hematology, WBC 12,000; Hg. 8.2 g Plat. C., 63,000

Assay no. 1

$1 / 18-3 / 17 / 58$

$1 / 18-3 / 17 / 58$

$1 / 18-3 / 18 / 58$

$3 / 20-5 / 7 / 58$

$3 / 20-5 / 7 / 58$

$3 / 20-5 / 7 / 58$

$5 / 7 / 58$

$9 / 25 / 57-1 / 8 / 58$

$9 / 25 / 57-1 / 8 / 58$

$9 / 25 / 57-1 / 8 / 58$

$1 / 7 / 58$

$1 / 7 / 58$

$1 / 7 / 58$ 
(j7: A.C. F 69 Type of leukemia: subacute

Precursor condition, polycythemia vera

1953-1955

Complications, diabetes mellitus, Orinase treatment; cholelithiasis

Prior treatment, X-ray to spleen

$1955-1956$

Recent treatment, X-ray to spleen

$10 / 16 / 57$

6-Mercaptopurine $25 \mathrm{mg} /$ day

Hematology, WBC 16,000 Plat. C., low

Assay no. 1

$10 / 17-10 / 21 / 57$

G8: G.J. F 69 Type of leukemia : subacute

Precursor condition, polycythemia vera

Complications, diabetes mellitus, insulin treatment; acute pancreatitis; cholelithiasis with operation

Recent treatment, Myleran $12 \mathrm{mg} /$ day

Red cell transfusions $500 \mathrm{ml}$

$10 / 21 / 57$

Hematology, WBC 16,000

Assay no. 1

$1955-1957$

$10 / 24 / 57$

$11 / 7-11 / 14 / 57$

$11 / 6 / 57$

$11 / 14 / 57$

G9: R.G.H. M 79 Type of leukemia: chronic

Recent treatment, Myleran $10 \mathrm{mg} /$ day

Hematology, WBC 68,000 ; Hg. 13.3 g Plat. C., 24,000

Assay no. 1

$9 / 18 / 58$

$9 / 19 / 58$

G10 : R.G.H. See above

Recent treatment, Myleran $10 \mathrm{mg} /$ day

Hematology, WBC 6,500; Hg. $13.0 \mathrm{~g}$

Assay no. 2

$9 / 18-10 / 7 / 58$

$11 / 20 / 58$

G11 : R.G.H. See above

Recent treatment, Myleran $6 \mathrm{mg} /$ day

Myleran $3 \mathrm{mg} /$ day

Myleran $2 \mathrm{mg} /$ day

Hematology, WBC 14,000

Assay no. 3

$2 / 10-3 / 10 / 59$

$3 / 10-5 / 1 / 59$

$5 / 1-5 / 7 / 59$

$5 / 7 / 59$

G12: C.W. F 43 Type of leukemia: chronic

Complication, acute streptococcal pharyngitis

$12 / 9 / 58$

Treatment, none

Hematology, WBC 25,000 ; Hg. 11.9 g Plat. C., 175,000

Assay no. 1

$12 / 8 / 58$

G13: J.W. M 60 Type of leukemia: chronic

Prior treatment, spray X-ray

$9 / 16 / 58$

Recent treatment, none

Hematology, WBC 46,000; Hg. 10.0 g Plat. C., 50,000

Assay no. 1

$5 / 8 / 59$

Monocytic leukemia

M1: P.C. M 79 Type of leukemia: chronic

Recent treatment, Chlorambucil, $10 \mathrm{mg} /$ day

Hematology, WBC 18,300; Hg. 10.1 g Plat. C., 1,000,000

$12 / 30 / 57-1 / 10 / 58$

Assay no. 1

$1 / 10 / 58$

M2: P.F. M 72 Type of leukemia: acute

Complication, acute rectal abscess

$1 / 15 / 59$

Treatment, none

Hematology, WBC 7,550; Hg. 9.7 g

Assay no. 1

$1 / 13 / 59$ 


\section{REFERENCES}

1. McMenamy, R. H., Lund, C. C., Neville, G. J., and Wallach, D. F. H. Studies of unbound amino acid distributions in plasma, erythrocytes, leukocytes and urine of normal human subjects. J. clin. Invest. 1960, 39, 0000.

2. Kelley, J. J., and Waisman, H. A. Quantitative plasma amino acid values in leukemic blood. Blood $1957,12,635$.

3. Nour-Eldin, F., and Wilkinson, J. F. Amino-acid content of white blood cells in human leukaemias. Brit. J. Haemat. 1955, 1, 358.

4. Rouser, G. Free or easily extractable amino acids in blood cells and body fluids in The Leukemias: Etiology, Pathophysiology and Treatment, J. W. Rebuck, F. H. Bethell, and R. W. Monto, Eds. New York, Academic Press, 1957, p. 361.

5. Iyer, G. Y. N. Paper-chromatographic study of free amino acids in normal and anaemic erythrocytes. Indian J. med. Res. 1957, 45, 213.

6. Cuthouse, E. L. Amino-ethyl phosphoric ester from tumours. Biochem. J. 1936, 30, 197.

7. White, J. M., Ozawa, G., Ross, G. A. L., and McHenry, E. W. An effect of neoplasms on glutamic acid metabolism in the host. Cancer Res. 1954, 14, 508 .

8. Roberts, E., and Tanaka, T. Free amino acids of the Yoshida ascites tumor. Cancer Res. 1956, 16, 204.
9. Meister, A. Biochemistry of the Amino Acids. New York, Academic Press, 1957, p. 292.

10. Gardella, J. W., and Lichtler, E. J. The effect of radiation on the nucleic acid, nitrogen, and water content of the Yoshida sarcoma. Cancer Res. 1955, 15, 529 .

11. Klein, G., and Forssberg, A. Studies on the effect of X-rays on the biochemistry and cellular composition of ascites tumors. I. Effect on growth rate, cell volume, nucleic acid and nitrogen content in the Ehrlich ascites tumor. Exp. Cell Res. 1954, 6, 211.

12. Katz, E. J., and Hasterlik, R. J. Aminoacidurea following total-body irradiation in the human. J. nat. Cancer Inst. 1955, 15, 1085.

13. Kay, R. E., Early, J. C., and Entenman, C. Increased urinary excretion of taurine and urea by rats after X-irradiation. Radiat. Res. 1957, 6, 98.

14. Fink, K., Henderson, R. B., and Fink, R. M. Betaaminoisobutyric acid, a possible factor in pyrimidine metabolism. Proc. Soc. exp. Biol. (N. Y.) 1951, 78, 135.

15. Awapara, J. Urinary acid excretion in leukemia in The Leukemias: Etiology, Pathophysiology, and Treatment, J. W. Rebuck, F. H. Bethell, and R. W. Monto, Eds. New York, Academic Press, 1957, p. 353 . 